\title{
PENERAPAN AKAD MUDHARABAH PADA PRODUK TABUNGAN DI PT. BANK SYARIAH MANDIRI KC PRABUMULIH
}

\author{
${ }^{1}$ Nora Pusvita Sari, ${ }^{2}$ Fadilla, ${ }^{3}$ Havis Aravik \\ ${ }^{1}$ Mahasiswa Perbankan Syariah, Sekolah Tinggi Ekonomi dan Bisnis Syariah (STEBIS) \\ Indo Global Mandiri, Email: nora_student@ stebisigm.ac.id \\ ${ }^{2}$ Sekolah Tinggi Ekonomi dan Bisnis Syariah (STEBIS) Indo Global Mandiri \\ Email: dilla@stebisigm.ac.id \\ ${ }^{3}$ Sekolah Tinggi Ekonomi dan Bisnis Syariah (STEBIS) Indo Global Mandiri \\ Email: havis@stebisigm.ac.id
}

\begin{abstract}
Sharia banking is currently on the rise and has become a reference for people to invest their funds for various needs. For this reason, various sharia banking products must be able to be understood by the public, one of which is the application of the mudharabah contract to savings products. This article discusses the application of the Mudharabah contract to savings products at PT. Bank Syariah Mandiri KC. Prabumulih. This article uses qualitative research by collecting data through direct interviews with stakeholders at Bank Syariah Mandiri Prabumulih Branch. The results of this study are the implementation of the contract used in planning savings is the mudharabah muthlaqah contract, which is a form of cooperation between shahibul maal (fund owner), namely the customer and mudharib (fund manager), namely the bank, where the owner of the fund (shahibul maal) does not impose limits on the mudharib in determine the type of business, time and area of business as long as it does not conflict with sharia principles and is in accordance with bank regulations.
\end{abstract}

Keywords: Application, Mudharabah Akad, Savings Products, Bank Syariah Mandiri

\begin{abstract}
Abstrak
Perbankan syariah saat ini sedang naik daun dan menjadi rujukan masyarakat untuk menginvestasikan dananya untuk berbagai kebutuhan. Untuk itu, berbagai produk perbankan syariah harus mampu dipahami masyarakat, salah satunya penerapan akad mudharabah pada produk tabungan. Artikel ini membahas tentang Penerapan Akad Mudharabah Pada Produk Tabungan Di PT. Bank Syariah Mandiri KC. Prabumulih. Artikel ini menggunakan penelitian kualitatif dengan pengambilan data melalui wawancara langsung dengan stakeholders di Bank Syariah Mandiri Cabang Prabumulih. Hasil penelitian ini adalah Penerapan akad yang digunakan dalam Tabungan berencana adalah akad mudharabah muthlaqah yaitu bentuk kerja sama antara shahibul maal (pemilik dana) yaitu nasabah dan mudharib (pengelola dana) yaitu bank, dimana pemilik dana (shahibul maal) tidak memberikan batasan kepada mudharib dalam menentukan jenis usaha, waktu dan daerah bisnis asalkan tidak bertentangan dengan prinsip syariah serta sesuai dengan ketentuan bank.
\end{abstract}

Kata Kunci: Penerapan, Akad Mudharabah, Produk Tabungan, Bank Syariah Mandiri 
212 | Nora Pusvita Sari, Fadilla, Havis Aravik, Penerapan Akad Mudharabah Pada Produk Tabungan.....

\section{DASAR PEMIKIRAN}

Perbankan adalah lembaga yang mempunyai peran utama dalam pembangunan suatu negara, peran ini terwujud dalam fungsi bank sebagai lembaga intermediasi keuangan (Financial Intermediary Institution), yakni menghimpun dana dari masyarakat dalam bentuk simpanan dan menyalurkan kepada masyarakat dalam bentuk kredit atau bentuk-bentuk lainnya dalam rangka meningkatkan taraf hidup masyarakat (Havis Aravik et al., 2020).

Bank umum adalah yang dapat memberikan jasa dalam lalu lintas pembayaran, dimana dalam melaksanakan kegiatan usahanya dapat secara konvensional atau berdasarkan prinsip syariah. Sebagaimana fungsi perbankan Indonesia, bank umum juga merupakan Agen of Devolepment yang bertujuan meningkatkan pemerataan, pertumbuhan ekonomi dan stabilitas nasional kearah peningkatkan kesejahteraan rakyat banyak (Hasibuan, 2001).

Sistem perbankan syariah telah membuktikan dirinya sebagai suatu sistem yang tengah melalui krisis ekonomi di Indonesia banyak keunggulan yang dimiliknya sehingga dapat bertahan menghadapi keadaan yang sangat sulit bagi dunia perbankan (H. Aravik, 2021). Di antara keunggulannya pertumbuhan perbankan dengan pertumbuhan ekonomi riil. Dalam kondisi krisis ekonomi misalnya, bank konvensional mengalami Negative Spread (Bunga simpanan lebih tinggi dari bunga pinjaman) dalam bisnisnya, sebagai suatu kondisi utama yang yang dihadapi oleh perbankan konvensional dan justru dalam kondisi demikian bank syariah menunjukkan kondisi sebaliknya (Rivai, 2007).

Pembiayaan adalah suatu fasilitas yang diberikan oleh bank syariah kepada masyarakat yang membutuhkan untuk menggunakan dana yang telah dikumpulkan oleh bank syariah dari masyarakat yang surplus dana (Muhammad, 2002). Menurut UndangUndang No. 10 Tahun 1998, pembiayaan merupakan penyediaan uang atau tagihan yang dapat dipersamakan, dengan itu berdasarkan persetujuan atau kesepakatan antara bank dengan pihak lain yang mewajibkan pihak yang dibiayai untuk mengembalikan uang atau tagihan tersebut dalam jangka waktu tertentu dengan imbalan atau bagi hasil (Kasmir, 2012). 
Fungsi bank syariah secara garis besar tidak berbeda dengan bank konvensional, yakni sebagai lembaga internediasi (Intermediary Institution) yang mengerahkan dana dari masyarakat dan menyalurkan kembali dana-dana tersebut kepada masyarakat yang membutuhkannya dalam bentuk fasilitas pembiayaan. Perbedaannya, bila bank konvensional mendasarkan keuntungannya dari pengambilan bunga, maka bank syariah dari apa yang disebut imbalan, baik berupa jasa (fee-base income) maupun mark-up atau profit margin, serta bagi hasil (loss and profit sharing).

Keberadaan bank syariah di Indonesia semakin kokoh dengan di undangkannya Undang-Undang Nomor 10 Tahun 1998 tentang Perubahan Atas Undang-Undang Nomor 7 Tahun 1992 tentang Perbankan. Undang-Undang ini cakupanya lebih luas, bahwa bank syariah tidak semata-mata adalah bank yang melakukan kegiatan usahanya berdasarkan bagi hasil melainkan bank yang memberikan produk-produknya berdasarkan prinsip syariah. Undang-Undang ini pula yang mengadopsi sistem perbankan ganda (Dual Banking System), sehingga suatu bank umum konvensional juga diberikan hak untuk memberikan layanan syariah kepada nasabah. Untuk melakukan hal itu terlebih dahulu perlu dibentuk Unit Usaha Syariah yaitu unit Kerja di kantor pusat bank umum konvensional yang berfungsi sebagai kantor induk dari kantor cabang syariah atau unit syariah (Bank Indonesia, 1998). Berdasarkan uraian tersebut maka penulis mengambil judul Penerapan Akad Mudharabah Pada Produk Tabungan di PT. Bank Syariah Mandiri KC Prabumulih.

\section{LANDASAN TEORI}

\section{Sejarah Bank Mandiri Syariah}

Kehadiran Bank Syariah Mandiri sejak tahun 1999, sesungguhnya merupakan hikmah sekaligus berkah pasca krisis ekonomi dan moneter 1997-1998. Sebagaimana diketahui, krisis ekonomi dan moneter sejak Juli 1997, yang disusul dengan krisis multidimensi termasuk di panggung politik nasional, telah menimbulkan beragam dampak negatif yang sangat hebat terhadap seluruh sendi kehidupan masyarakat, tidak terkecuali dunia usaha. Dalam kondisi tersebut, industri perbankan nasional yang didominasi oleh bank-bank konvensional mengalami krisis luar biasa. Pemerintah akhirnya mengalami 
tindakan dengan merestrukturisasi dsan merekapilitasasi sebagian bank-bank di Indonesia.

Pada saat bersamaan, pemerintah melakukan penggabungan (merger) empat bank (Bank Dagang Negara, Bank Bumi Daya, Bank Exim, dan Bapindo) menjadi satu bank baru bernama PT. Bank Mandiri (Persero) pada tanggal 31 Juli 1999. Kebijakan penggabungan tersebut juga menempatkan dan menetapkan PT. Bank Mandiri (Persero) Tbk. Sebagai pemilik mayoritas baru BSB.

Sebagai tindak lanjut dari keputusan merger, Bank Mandiri Syariah melakukan konsolidasi serta membentuk Tim Pengembangan Perbankan Syariah. Pembentukan tim ini bertujuan untuk mengembangkan layanan perbankan syariah di kelompok perusahaan Bank Mandiri Syariah, sebagai respon atas diberlakukannya UU No. 10 Tahun 1998, yang memberi peluang bank umum untuk melayani transaksi syariah (Dual Banking System).

Tim pengembangan Perbankan Syariah memandang bahwa pemberlakuan UU tersebut merupakan momentum yang tepat untuk melakukan konversi PT. Bank Susila Bakti dari bank konvensional menjadi bank syariah. Oleh karenanya, Tim Pengembangan Perbankan Syariah segera mempersiapkan sistem dan insfrastrukturnya, sehingga kegiatan usaha BSB berubah dari bank konvensional menjadi bank yang beroperasi berdasarkan prinsip syariah dengan nama PT. Bank Syariah Mandiri sebagaimana tercantum dalam Akta Notaris: Sujipto, SH, No. 23 tanggal 8 September 1999. Perubahan kegiatan usaha BSB menjadi bank umum syariah dikukuhkan oleh Gubernur Bank Indonesia melalui SK Gubernur BI No. 1/24/KEP.BI/1999, 25 Oktober 1999. Selanjutnya, melalui Surat Keputusan Deputi Gubernur Senior Bank Indonesia No. 1/1/KEP.DGS/1999, BI menyetujui perubahan nama menjadi PT. Bank Syariah Mandiri. Menyusul pengukuhan dan pengakuan legal tersebut, PT. Bank Syariah Mandiri secara resmi mulai beroperasi sejak Senin tanggal 25 Rajab $1420 \mathrm{H}$ atau tanggal 1 November 1999.

PT. Bank Syariah Mandiri hadir tampil dan tumbuh sebagai bank yang mampu memadukan idealisme usaha dengan nilai-nilai rohani inilah yang menjadi salah satu keunggulan Bank Syariah Mandiri dalam kiprahnya di perbankan Indonesia. Bank 
Syariah Mandiri hadir untuk bersama membangun Indonesia menuju Indonesia yang lebih baik (Syariah Mandiri, 2020).

\section{Pengertian Akad Mudharabah}

Akad adalah kontrak antara dua belah pihak, dimana akad mengikat kedua belah pihak yang saling bersepakat, yakni masing-masing pihak terikat untuk melaksanakan kewajiban mereka masing-masing yang telah di sepakati (Karim, 2009). Secara praktek, akad mudharabah pernah dilakukan oleh Nabi Muhammad SAW ketika bekerjasama dengan Siti Khadijah sebelum Muhammad SAW diangkat menjadi seorang Nabi dan Rasul. Kala itu Siti Khadijah berperan sebagai pemilik modal (shahibul maal) sedangkan Nabi Muhammad SAW berperan sebagai pelaksana usaha (mudharib). Disana Siti Khadijah mempercayakan barang dengannya untuk dijual Nabi Muhammad SAW. ke luar negeri (Hamzani, A. I., \& Aravik, 2021).

Akad Mudharabah merupakan salah satu akad yang sangat penting dan diatur dalam al-Qur'an. Sebagaimana firman Allah SWT dalam Surat an-Nisa' [4] ayat 29

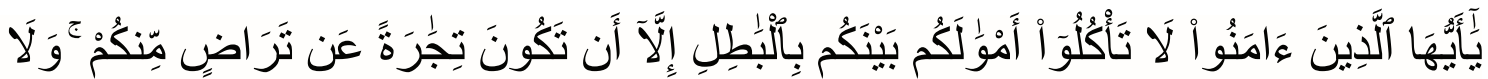

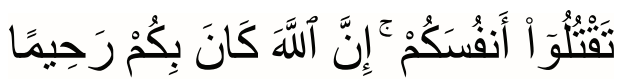

Artinya: Hai orang-orang yang beriman, janganlah kamu saling memakan harta sesamamu dengan jalan yang batil, kecuali dengan jalan perniagaan yang berlaku dengan suka sama-suka di antara kamu. Dan janganlah kamu membunuh dirimu; sesungguhnya Allah adalah Maha Penyayang kepadamu.

\section{METODE PENELITIAN}

Penelitian ini merupakan penelitian kualitatif. Data yang diperoleh dalam penelitian ini merupakan data primer karena berdasarkan wawancara langsung kepada stakeholders di Bank Syariah Mandiri Cabang Prabumulih. 
216 | Nora Pusvita Sari, Fadilla, Havis Aravik, Penerapan Akad Mudharabah Pada Produk Tabungan.....

\section{HASIL DAN PEMBAHASAN}

\section{Mekanisme Penghimpunan Dana Bank Mandiri Syariah}

Mekanisme penghimpunan Dana Bank Mandiri Syariah di lihat dari Brosur Bank Syariah Mandiri (Brosur Bank Syariah Mandiri, 2020), antara lain:

1. Tabungan Mudharabah Berkah

Tabungan dalam mata uang rupiah yang penarikan dan setorannya dapat dilakukan setiap saat selama jam kas di buka di konter Bank Syariah Mandiri atau melalui ATM.

Tabungan Mudharabah Berkah sangat bermanfaat, seperti di bawah ini :

a. Aman dan terjamin

b. Kemudahan bertransaksi di seluruh outlet Bank Syariah Mandiri

c. Kemudahan bertransaksi dimana saja menggunakan layanan e-Banking

d. Kemudahan dalam menyalurkan Zakat, Infaq dan Sedekah

Persyaratan tabungan Mudharabah berkah antara lain:

1) Perorangan : KTP \& NPWP

2) Perusahaan : Daftar susunan pengurus, KTP pengurus, Akta pendirian, SIUP, SITU \& NPWP, TDP, laporan keuangan

Sedangkan fitur tabungan mudharabah berkah yaitu:

1) Berdasarkan prinsip syariah dengan akad Mudharabah Muthlaqah

2) Setoran awal minimum

- Perorangan Rp. 100.000 (mendapatkan Mandiri Syariah debit)

- Non perorangan Rp. 1.000.000 (tidak mendapat Mandiri Syariah debit)

3) Saldo minimum Rp. 50.000

4) Minimum setoran berikutnya Rp. 10.000

5) Biaya administrasi Rp. 10.000

6) Biaya penutupan rekening Rp. 20.000

7) Biaya penggantian buku tabungan karena hilang atau rusak Rp. 10.000

2. Tabungan Investa Cendekia

Tabungan berjangka untuk keperluan uang pendidikan dengan jumlah setoran bulanan tetap (installment) dan dilengkapi dengan perlindungan ansuransi. Disini nasabah dapat memilih jangka waktu tabungan yang di tawarkan oleh BSM sesuai 
dengan kebutuhan nasabah yang akan secara langsung diikut sertakan kedalam asuransi yaitu Asuransi Takaful tanpa pemeriksaan kesehatan dengan potongan premi tiap bulannya sesuai dengan jangka waktu tabungan.

\begin{tabular}{|c|c|}
\hline Jangka Waktu Menabung & Premi \\
\hline 0-5 Tahun & $2,5 \%$ \\
\hline 6-10 Tahun & $3,75 \%$ \\
\hline 11-15 Tahun & $5 \%$ \\
\hline 16-20 Tahun & $6,5 \%$ \\
\hline
\end{tabular}

Apabila Penabung menunggak setoran bulanan (installment) selama 3 (tiga) bulan berturut-turut, maka manfaat atas perlindungan asuransi otomatis gugur, dan setoran untuk bulan-bulan selanjutnya otomatis berakhir, namun dana yang telah disetorkan pada bulan-bulan sebelumnya dikembalikan kepada nasabah yang bersangkutan dengan menyetor ke rekening penabung, dengan begitu tidak terdapat unsur gharar (ketidak jelasan) dalam produk ini karena uang nasabah tersebut dikembalikan.

Adapun persyaratan tabungan cendekia, antara lain:

1) KTP, NPWP

2) Minimum usia 17 tahun dan maksimum 55 tahun (usia masuk ditambah periode kontrak sama atau tidak lebih melebihi 60 tahun)

3) Memiliki rekening tabungan / giro sebagai rekening asal (source account)

Sedangkan fitur tabungan cendekia yaitu:

a) Berdasarkan prinsip syariah dengan akad mudharabah muthlaqah

b) Setoran bulanan minimum Rp. 100.000, maksimum Rp. 10.000 .000

c) Biaya administrasi bulanan gratis

d) Biaya penutupan rekening setelah jatuh tempo gratis

e) Biaya penutupan rekening sebelum jatuh tempo Rp. 100.000

f) Biaya penggantian buku tabungan karena hilang atau rusak Rp. 10.000

g) Periode tabungan 1 s.d. 20 tahun

Fungsi dari Tabungan Investa Cendekia ini bagi nasabah adalah nasabah bisa mempersiapkan dana pendidikan sedini mungkin dan merupakan tindakan yang bijaksana. Melalui Tabungan Investa Cendekia dari Bank Syariah Mandiri ini pula nasabah dapat merencanakan dana pendidikan si buah hati secara tepat dan cermat yang 
218 | Nora Pusvita Sari, Fadilla, Havis Aravik, Penerapan Akad Mudharabah Pada Produk Tabungan.....

mana secara otomatis diikutsertakan ke dalam asuransi dengan premi terendah hanya 2,5\% - 6,5\% tiap setoran per bulannya. Dengan adanya perlindungan asuransi ini maka kelangsungan biaya pendidikan buah hati nasabah lebih terjamin.

Sedangkan fungsi Tabungan Investa Cendekia ini bagi pihak Bank ialah, dikarenakan tabungan ini menggunakan akad Mudharabah Muthalaqah (investasi tidak terikat) yang artinya pihak Bank dapat memanfaatkan dana dari nasabah untuk disalurkan atau diberikan secara kredit untuk usaha tertentu dan nasabah mendapatkan bagi hasil yang kompetitif. Berarti dalam hal ini nasabah mengetahui bahwa dana tabungan yang ia titipkan dapat digunakan oleh pihak Bank dan nasabah mendapatkan bagi hasil yang kompetitif.

Bagi hasil TIC diperhitungkan berdasarkan saldo rata-rata harian dan akan dibukukan ke Rekening TIC Penabung. Bank dapat merubah dan menetapkan bagi hasil baru yang akan diinformasikan melalui papan pengumuman di counter cabang Bank akan berlaku pada awal bulan berikutnya. Bila dalam 10 (sepuluh) hari kalender setelah pengumuman tersebut dikeluarkan Penabung tidak mengajukan keberatan secara tertulis disertai pembatalan keikutsertaannya pada program TIC, maka Penabung dianggap dapat menyetujui perubahan besaran bagi hasil tersebut (Dokumentasi, 2020).

\section{Tabungan Mabrur Berkah}

Tabungan Mabrur merupakan salah satu produk pendanaan dari Bank Syariah Mandiri yang bertujuaan untuk membantu pelaksanaan ibadah haji dan umrah. Dengan setoran awal ringan dan berdasarkan prinsip syariah dengan menggunakan akad mudharabah mutlaqah, dimana nasabah akan mendapatkan bagi hasil yang kompetitif berdasarkan nisbah yang ditetapkan oleh bank. Sedangkan manfaat tabungan mabrur berkah antara lain:

1) Aman dan terjamin

2) Mendapatkan fasilitas reminder notifikasi saldo

3) Cover asuransi $\geq$ Rp. 5.000.000

Adapun persyaratan tabungan mabrur berkah yaitu:

1) WNI 
2) $\mathrm{KTP}$

3) NPWP

Sementara fitur tabungan mabrur berkah yaitu:

1) Berdasarkan prinsip syariah dengan akad mudharabah muthlaqah

2) Setoran awal minimum Rp. 100.000

3) Saldo minimum Rp. 100.000

4) Minimum setoran berikutnya Rp. 100.000

5) Biaya administrasi tidak ada

6) Biaya penutupan rekening Rp. 20.000

7) Jumlah saldo yang di daftarkan ke siskohat Rp. 25.100.000

8) Biaya penggantian buku tabungan karena hilang atau rusak Rp. 10.000

9) Nasabah tidak diperbolehkan melakukan penarikan saldo tabungan mabrur berkah kecuali dalam keadaan darurat misalnya nasabah mendapatkan musibah atau kemalangan.

Berdasarkan peraturan Kementerian Agama mengenai tata cara pendaftaran pelaksanaan haji, yaitu mewajibkan calon jamaah haji memilih salah satu bank yang telah resmi menjadi Bank Penerima Setoran Biaya Pendaftaran Ibadah Haji (BPS BPIH). Dengan peraturan tersebut sangat membantu perkembangan perbankan syariah dan khususnya untuk produk tabungan mabrur yang dimiliki oleh Bank Syariah Mandiri KC Prabumulih.

Tabungan ini menggunakan akad mudharabah mutlaqah dimana akad tersebut menerapkan prinsip bagi hasil atas keuntungan yang di dapat dan sesuai dengan nisbah yang telah disepakati. Tabungan Mabrur milik Bank Syariah Mandiri lebih menguntungkan bagi nasabah, karena bagi hasil yang presentasenya lebih besar dibandingkan dengan bank syariah lain yaitu sebesar $25 \%$ dan biaya penutupan rekening karena pembatalan juga lebih murah yaitu sebesar Rp. 25.000 sedangkan pada Bank Muamalat Indonesia Rp. 50.000 dan Bank Mega Syariah sebesar Rp. 100.000

Berdasarkan hasil wawancara terhadap Ibu Gita Cahyaning yang menjabat sebagai Back Office di Bank Syariah Mandiri KC Prabumulih, strategi pelayanan produk Tabungan Mabrur dalam meningkatkan loyalitas nasabah dapat dilihat dari dimensi kualitas pelayanan, yaitu sebagai berikut: 
220 Nora Pusvita Sari, Fadilla, Havis Aravik, Penerapan Akad Mudharabah Pada Produk Tabungan.....

1) Keandalan (realibility)

2) Daya Tanggap (responsiveness)

Masing-masing karyawan memiliki tanggung jawab yang berbeda-beda, yang salah satu tugasnya untuk melayani nasabah. Setiap karyawan mampu untuk memberikan pelayanan yang dijanjikan dengan segera, serta memberikan pelayanan dengan tanggap. Seperti misalnya, jika disaat proses pembukaan rekening, calon nasabah tabungan mabrur mengalami kesulitan dalam pengisian formulir, pihak Bank Syariah Mandiri akan membantu menuliskan data, agar proses lebih cepat.

3) Jaminan (assurance)

Karyawan Bank Syariah Mandiri memiliki pengetahuan kompetensi dalam bidangnya masing-masing, hal ini dilakukan agar nasabah mempercayai pihak BSM. Dalam hal ini tentang Tabungan Mabrur di harapkan bahwa karyawan terutama customer service benar-benar paham tentang produk Tabungan Mabrur agar dapat menjelaskan kepada nasabah dengan baik dan lugas.

4) Kepedulian (emphaty)

Meliputi pemahaman atas kebutuhan individu para pelanggan atau nasabah, komunikasi yang baik dan perhatian pribadi. Kaitannya dengan pelayanan produk Tabungan Mabrur yaitu setelah nasabah memperoleh setoran awal BPIH, nasabah tersebut harus menyerahkan data BPIH tersebut ke Departemen Agama Kota Prabumulih, jika nasabah tersebut usianya sudah cukup tua (lansia) atau dalam kondisi sakit pihak Bank Syariah Mandiri KC Prabumulih akan membantu mengantarkan ke kantor Departemen Agama Kota Prabumulih tanpa dipungut biaya apapun. Hal ini diharapkan dapat membangun loyalitas nasabah produk Tabungan Mabrur.

5) Bukti Fisik (Tangible)

Pada saat nasabah Tabungan Mabrur datang ke kantor Bank Syariah Mandiri Kc Prabumulih, karyawan Bank Syariah Mandiri KC Prabumulih terutama customer service berpenampilan menarik, rapi dan bersih, bertutur kata yang sopan dan lemah lembut. Hal ini diharapkan mampu membangun loyalitas nasabah Tabungan Mabrur.

6) Pemenuhan (compliance)

Tabungan Mabrur adalah salah satu produk pendanaan dari Bank Syariah Mandiri yang bertujuaan untuk membantu pelaksanaan ibadah haji dan umrah. Dengan setoran 
awal ringan dan berdasarkan prinsip syariah dengan menggunakan akad mudharabah mutlaqah, dimana nasabah akan mendapatkan bagi hasil yang kompetitif berdasarkan nisbah yang ditetapkan oleh bank.

7) Kepuasan (satisfaction)

Pada saat proses pembukaan rekening sampai penyerahan setoran awal BPIH sudah selesai, pihak Bank Syariah Mandiri KC Prabumulih akan memberikan hadiah menarik kepada nasabah. Hal ini sebagai tanda wujud terima kasih pihak Bank Syariah Mandiri KC Prabumulih kepada nasabah Tabungan Mabrur atas kepercayaan yang sudah diberikan.

Dari uraian di atas, dapat disimpulkan bahwa terdapat tujuh dimensi kualitas pelayanan Tabungan Mabrur BSM dan produk Tabungan Mabrur BSM lebih menekankan pada proses pembukaan rekening dengan cepat dan mudah serta kesanggupan pihak BSM membantu nasabah yang kesulitan dalam proses pembukaan rekening dan penyerahan data BPIH ke kantor Departemen Agama Kota Prabumulih (Wawancara dengan Pegawai BSM Ibu Gita Cahyaning (Back Office), Pada Tanggal 23-25 November 2020).

\section{Tabungan Berencana Berkah}

Tabungan berjangka untuk berbagai rencana anda yang memberikan nisbah bagi hasil berjenjang dan memiliki perlindungan asurabsi secara gratis. Tabungan Berencana di mana karakteristiknya adalah jumlah minimal tertentu yang hampir sama dengan tabungan biasa, namun nasabah wajib menyetorkan dananya secara rutin melalui tabungan tersebut sesuai dengan perjanjian sebelum menabung, dan sesuai kemampuan membayarnya, serta tidak boleh di ambil sebelum jatuh tempo yang ditentukan nasabah. Untuk bagi hasil dari Tabungan Berencana ini biasanya akan lebih besar dari pada tabungan biasa dan lebih kecil dari Tabungan deposito. Dan dalam tabungan berencana ini ada perlindungan asuransi gratis didalamnya.

Manfaat yang diperoleh dari tabungan berencana berkah, antara lain:

1) Bagi hasil yang kompetitif

2) Kemudahan perencanaan keuangan nasabah jangka panjang

3) Perlindungan asuransi secara gratis dan otomatis tanpa pemeriksaan kesehatan 
4) Jaminan perencapaian target dana

Persyaratan tabungan berencana berkah

1) KTP, NPWP \& Minimum usia 17 tahun

2) Usia maks 60 tahun saat pembukaan rekening \& 65 tahun saat jatuh tempo

3) Memiliki rekening tabungan / giro sebagai rekening asal (source account)

Sedangkan fitur tabungan berencana berkah sebagai berikut:

1) Berdasarkan prinsip syariah dengan akad mudharabah muthlaqah

2) Setoran bulanan minimum Rp. 100.000

3) Biaya administrasi bulanan gratis

4) Biaya penutupan rekening setelah jatuh tempo gratis

5) Biaya penutupan rekening sebelum jatuh tempo Rp. 100.000

6) Biaya penggantian buku tabungan karena hilang atau rusak Rp. 10.000

7) Periode tabungan 1 s.d. 10 tahun.

\section{Nisbah Bagi hasil}

Bagi hasil adalah pembagian atas hasil usaha yang telah dilakukan oleh pihak pihak yang melakukan perjanjian yaitu pihak nasabah dan pihak bank syariah. Bagi hasil dari tabungan berencana dikenal dengan istilah "Nisbah". Nasabah bisa menanyakan kepada bagian custumer service bank syariah berapa nisbah bagi hasilnya tetapi biasanya custumer service sudah memberikan penjelasan tentang tabungan berencana dan juga nisbah bagi hasil yang sudah ditentukan oleh pihak bank tersebut.

Dalam tabungan berencana, penabung akan mendapatkan bagi hasil sesuai dengan kesepakatan yang dibuat antara bank dengan penabung (nasabah). Adapun nisbah bagi hasil dari tabungan berencana adalah berjenjang (pembagian bagi hasil antara penabung dan bank atas pendapatan yang diperoleh bank dari pengelolaan dana penabung sesuai kesepakatan antara bank dan penabung diawal akad). Dapat dilihat tabel nisbah bagi hasil dari tabungan berencana berikut ini:

Nisbah Bagi Hasil

\begin{tabular}{|c|c|}
\hline Saldo Rata-Rata & Nisbah \\
\hline$<25 \mathrm{Jt}$ & $43 \%$ \\
\hline
\end{tabular}




\begin{tabular}{|c|c|}
\hline $25 \leq 50 \mathrm{Jt}$ & $44 \%$ \\
\hline $50 \leq 75 \mathrm{Jt}$ & $45 \%$ \\
\hline $75 \leq 100 \mathrm{Jt}$ & $46 \%$ \\
\hline$>100 \mathrm{Jt}$ & $48 \%$ \\
\hline
\end{tabular}

Contoh Perhitungan nisbah bagi hasil tabungan berencana yaitu: Saldo rata-rata Tabungan Berencana yang dimiliki oleh Ibu Siti pada bulan Mei adalah Rp. 1.200.000 Nisbah bagi hasilnya adalah 43\% (karena saldo tabungannya $<25$ juta). Kemudian saldo rata-rata tabungan seluruh nasabah BSM adalah Rp.800.000.000 dan pendapatan bank yang dibagihasilkan untuk nasabah tabungan berencana Rp. 24.000.000 Berapa bagi hasil yang diterima oleh Ibu Siti pada bulan tersebut? Jawaban: 1.200.000 / $800.000 .000 \times 24.000 .000 \times 43 \%=R p 15.480$ Berdasarkan perhitungan diatas, besar bagi hasil yang diterima oleh Ibu Siti selama satu bulan untuk tabungan dengan saldo rata-rata Rp1.200.000 adalah Rp. 15. 480

Berdasarkan hasil penelitian dan wawancara di PT. Bank syariah mandiri KC Prabumulih dengan narasumber Lufthi Rakarianda selaku Customer Service juga menyimpulkan bahwa penerapan akad mudharabah muthlaqah pada tabungan berencana di PT. Bank Syariah Mandiri KC Prabumulih sudah sesuai dengan prinsip syariah. Sehingga setiap bank harus menerapkan akad sesuai dengan prinsip syariah sebagai dasar dalam suatu produk untuk memberikan salah satu fasilitas kepada nasabah. Akad yang diterapkan dalam Tabungan Berencana di bank syariah mandiri yaitu akad mudharabah muthlaqah.

Mudharabah Muthlaqah (investasi tidak terikat) yaitu pihak pengusaha diberi kuasa penuh untuk menjalankan usaha tanpa larangan/gangguan apapun urusan yang berkaitan dengan usaha itu, dan mudharib diberikan kebebasan penuh untuk mengelola tanpa terikat jenis usaha, waktu, dan daerah bisnis asalkan tidak bertentangan dengan prinsip syariah serta sesuai dengan ketentuan bank. Dalam hal ini nasabah bertindak sebagai shahibul maal dan pihak bank sebagai mudharib dan harus ada kesepakatan mengenai jangka waktu dan penarikan antara nasabah dan bank agar dana dapat diputar oleh bank (Wawancara dengan Pegawai BSM Kak Lufthi Rakarianda (Costomer Service), Pada Tanggal 26-27 November 2020). 


\section{SIMPULAN}

Berdasarkan paparan di atas, dapat disimpulkan bahwa:

a. Strategi pelayanan Tabungan Mabrur dalam meningkatkan loyalitas nasabah Bank Syariah Mandiri KC Prabumulih, antara lain: Karyawan berpenampilan rapi, bersih dan menarik. Kemudahan dalam proses pembukaan rekening dan termasuk jika terjadi kesulitan dalam setoran awal BPIH, memberikan hadiah menarik kepada nasabah setia Tabungan Mabrur, memaksimalkan kerjasama dengan instansi yang terkait produk Tabungan Mabrur (Departemen Kota Prabumulih).

b. Penerapan akad yang digunakan dalam Tabungan berencana adalah akad mudharabah muthlaqah yaitu bentuk kerja sama antara shahibul maal (pemilik dana) yaitu nasabah dan mudharib (pengelola dana) yaitu bank, dimana pemilik dana (shahibul maal) tidak memberikan batasan kepada mudharib dalam menentukan jenis usaha, waktu dan daerah bisnis asalkan tidak bertentangan dengan prinsip syariah serta sesuai dengan ketentuan bank. Dalam penerapan akad mudharabah muthlaqah pada tabungan berencana di PT. Bank syariah mandiri KC Prabumulih sudah sesuai dengan aturan dan prinsip syariah, perhitungan bagi hasil dari tabungan berencana tidak selalu sama setiap bulannya, karena dipengaruhi oleh pendapatan bank, nisbah tabungan berencana, saldo rata-rata tabungan berencana dan periode jangka waktunya. 


\section{DAFTAR PUSTAKA}

Aravik, H. (2021). Etika Perbankan Syariah: Teori dan Implementasi. Deepublish.

Aravik, Havis, Sulastyawati, D., \& Yunus, N. R. (2020). Leadership Concept At Sharia Bank ; 5, 21-32.

Bank Syariah Mandiri. (2020). Profil Bank Syariah Mandiri.

Brosur Bank Syariah Mandiri. (2020).

Dokumentasi. (2020). Bank Syariah Mandiri Kantor Cabang Prabumulih.

Hamzani, A. I., \& Aravik, H. (2021). POLITIK ISLAM: Sejarah dan Pemikiran. Penerbit NEM.

Hasibuan, M. S. . (2001). Dasar-Dasar Perbankan. Bumi Aksara.

Indonesia, B. (1998). Undang-Undang Nomor 10 Tahun 1998 tentang perubahan Undang-Undang Nomor 7 Tahun 1992 tentang Perbankan.

Karim, A. A. (2009). Bank Islam; Analisis Fiqih dan Keuangan. PT. Raja Grafindo Persada.

Kasmir. (2012). Manajemen Perbankan. PT. Raja Grafindo Persada.

Muhammad. (2002). Bank dan Lembaga Umat Kontemporer. UII Press.

Rivai, V. (2007). Bank and Financial Institution Management Convensional and Syar'i System. PT Raja Grafindo Persada. 
226 Nora Pusvita Sari, Fadilla, Havis Aravik, Penerapan Akad Mudharabah Pada Produk Tabungan..... 